\title{
Preventing depression and promoting resilience: feasibility study of a school-based cognitive-behavioural intervention
}

\author{
Paul Stallard and Rhiannon Buck
}

\section{Background}

The limited reach and effectiveness of psychological treatments for adolescent depression have fuelled interest in alternative approaches designed to promote resilience. schools offer a convenient location for the widespread delivery of depression prevention programmes, although little research has evaluated the feasibility of delivering interventions in this setting.

\section{Aims}

To investigate the feasibility of delivering and evaluating a universal school-based depression prevention programme for children aged $12-16$ years.

\section{Method}

A three-arm pilot study was conducted in one UK secondary school $(n=834)$.

\section{Results}

Interventions had good reach (96\%), with high rates of consent $(89 \%)$ and reasonable retention $(78 \%)$. The majority of intervention sessions were delivered as intended, with $85 \%$ of students attending seven or more sessions. The programme was acceptable to students and teachers, with the specific content of the active intervention being rated differently from the control programmes.

\section{Conclusions}

Delivering and undertaking methodologically robust evaluations of universal school-based depression programmes is feasible.

\section{Declaration of interest}

None.
The prevalence of depressive disorders in the UK in children (under 13 years old) and adolescents (aged 13-18 years) has been estimated at $2.8 \%$ and $5.6 \%$ respectively. ${ }^{1}$ These disorders have a significant adverse impact on school, social and family functioning and increase the risk of suicide and substance misuse in young adulthood. ${ }^{1-4}$ Depressive disorders persist over time and there is continuity between adolescent depression and depressive disorders in young adults. ${ }^{5}$ Relapse is common, with up to $70 \%$ of adolescents with depression experiencing a recurrent depressive episode within 5 years. ${ }^{6,7}$ Randomised controlled trials have demonstrated that effective psychological interventions are available for the treatment of depression in adolescents, at least in the short term. ${ }^{8-10}$ Although this is encouraging, the majority of adolescents with depression remain unidentified and untreated. ${ }^{11,12}$ The limited reach and effectiveness of current treatment programmes have led researchers to investigate whether depressive disorders can be prevented through the widespread provision of prevention programmes.

Prevention programmes tend to be conceptualised by their intended focus, either universal (provided to whole populations regardless of risk status) or targeted (e.g. provided to those at increased risk of developing depression). Universal programmes tend to be less stigmatising and have good reach, whereas targeted approaches tend to produce larger treatment effects and from a public health perspective may represent a better use of limited resources. ${ }^{13}$ For adolescents, schools provide a natural and convenient location for the delivery of mental health prevention programmes. Recognition of the potential role of schools in promoting mental health has been emphasised in recent UK government initiatives such as Targeted Mental Health in Schools and Social and Emotional Aspects of Learning. ${ }^{14,15}$

Although schools offer a potentially convenient way of accessing large numbers of young people, the effects of mental health programmes delivered in such settings have not always been positive. ${ }^{16-18}$ Variations between studies have been investigated in systematic reviews which have highlighted a number of issues. First, in terms of delivery, targeted depression prevention programmes tend to produce larger post-treatment effects than universal programmes. ${ }^{19,20}$ However, practically targeted programmes may prove more difficult to provide, since individual students need to be identified and additional arrangements made within the school to deliver the intervention. This might be difficult for busy secondary schools with limited space, which typically organise and plan timetables around year groups and classes rather than individual students. Second, sufficient time needs to be made available to deliver depression prevention programmes, which usually require $8-16$ sessions. ${ }^{20,21}$ Finding sufficient dedicated time within an already full timetable can be a practical problem that might prohibit their use in schools. Third, the majority of depression prevention programmes are based on cognitive-behavioural therapy (CBT) and tend to be more effective when delivered by mental health practitioners rather than trained school staff. ${ }^{20}$ Although programmes are more likely to be sustainable if delivered by educational staff, teachers might not necessarily feel sufficiently skilled or knowledgeable about CBT or comfortable talking about mental health issues. However, if programmes are externally provided then school and classroom staff need to be supportive of their delivery. Fourth, undertaking robust research evaluations of prevention programmes in schools is complicated and many existing studies suffer from significant methodological weakness. ${ }^{13,19,22}$ In order for results to be meaningful, school-based studies need to achieve good recruitment and retention rates, and assessments need to be acceptable and easily completed. Finally, the identification of appropriate comparison groups is an important issue for school trials. ${ }^{22}$ Comparison groups need to be appropriate and acceptable to the school. In addition they need to be matched for any possible non-specific elements such as increased attention 
and assessment completion, and assessed to ensure that the content of the programmes delivered to the intervention and comparison groups are sufficiently different.

The aim of this study was to examine the feasibility and acceptability of delivering and evaluating a depression prevention programme for adolescents within the UK educational context.

\section{Method}

Promoting Mental Health in Schools through Education (PROMISE) is a randomised controlled trial evaluating the effectiveness of a school-based depression programme for young people aged 12-16 years. ${ }^{23}$ To maximise fit with schools and minimise timetabling problems the programme was universally provided to whole classes of young people. However, the focus of the evaluation of the effectiveness of the programme was on students who had persistent and elevated levels of depressive symptoms, defined as a score of 5 or over on the Short Mood and Feelings Questionnaire (SMFQ), ${ }^{24}$ completed on two occasions 2 weeks apart.

\section{Ethical approval and consent}

The study was approved by the University of Bath ethical committee with consent/assent involving three stages. First, interested schools were required to opt into the study. Second, parents or carers of all students in years 8-11 (aged 12-16 years) on the school roll were sent a project information sheet and invited to return an opt-out form if they did not wish their child to complete the project assessments. Finally, young people were required to sign a consent form before completing assessment questionnaires.

\section{Recruitment}

Information about the project was sent to 66 non-denominational comprehensive secondary schools in Bath and north-east Somerset, Bristol, Wiltshire, Nottingham and Nottinghamshire. Nine schools were recruited, one for the pilot study and eight for the main trial.

\section{Intervention}

The PROMISE study is a randomised controlled trial with the following three trial arms.

\section{Resourceful Adolescent Programme}

The Resourceful Adolescent Programme (RAP) is a depression prevention programme based on CBT designed to be delivered to whole classes of young people aged 12-15 years. It has been subjected to evaluations in Australia, New Zealand and Mauritius. ${ }^{25-28}$ The original 11-session programme was adapted for use in the UK educational system and consisted of 9 sessions facilitating the development of skills in six main areas. First, the participants were encouraged to identify and recognise their personal strengths and the importance of maintaining good selfesteem and positive mood. The second area focused on cognitions and encouraged adolescents to identify, check and challenge unhelpful cognitions and to replace them with more balanced, enabling and helpful ways of thinking. Emotional management was the third area, facilitating emotional recognition and the development of emotional management strategies. The fourth focused on the development of problem-solving skills and the fifth on identifying support networks to draw upon to help with problems. The final section was concerned with keeping the peace and how to use these skills to resolve interpersonal problems and to promote harmony. The programme involved a mix of largegroup discussion, role play and small-group exercises, and each young person was given a workbook summarising key issues and messages.

The sessions were led by two facilitators working alongside the class teacher. Facilitators had at least an undergraduate university degree in a relevant discipline and all had experience of working with young people. All received initial training in the cognitive model of depression and RAP and attended ongoing supervision sessions.

\section{Attention control group}

As part of the national curriculum schools provide personal, social and health education (PSHE). The curriculum covers a range of topics relating to citizenship and psychological well-being, including drug and sexual education, human rights, diversity, difference and discrimination. The class teacher leads the sessions and in this trial was supported by two facilitators. The group was matched for time (9 sessions) and adult contact with the RAP group.

\section{Usual PSHE}

Young people participated in the usual PSHE sessions provided by the school (i.e. treatment as usual). The sessions were provided solely by the teachers.

\section{Primary outcome}

The primary outcome was change in symptoms of low mood at 12 months as assessed with the SMFQ, a 13-item measure of symptoms of low mood and depression. ${ }^{24}$

\section{Other measures}

In order to assess whether the contents of RAP and usual PSHE were different, lesson facilitators were asked independently to assess the content of each session on a 5-point scale ranging from 'not at all' (0) to 'a lot' (4). At the conclusion of the programme, feedback concerning RAP was obtained from students by means of individual semi-structured interviews and from teachers through focus group discussion.

\section{Results}

The feasibility study was conducted in one mixed-gender, nondenominational secondary school. The students' educational attainment, eligibility for free school meals and absence rates were comparable to the national average (Table 1); however, fewer children were identified with special educational needs or from minority ethnic backgrounds.

\section{Recruitment and retention}

In terms of eligibility, 801 (96\%) students on the school roll were attending school and were therefore able to participate in the study (Fig. 1). The consent process appeared acceptable, with dual parent and young person consent to complete the assessment measures being obtained for $713(89 \%)$ students. Both screening and baseline assessments were completed by $624(88 \%)$ of those who consented, of whom $552(88 \%)$ completed the 6-month assessment and $489(78 \%)$ completed the final 12-month assessment. Twelve-month retention rates in years 8 (91\%), 9 $(90 \%)$ and $10(83 \%)$ were good, but there was a particular problem with year $11(45 \%)$; these students had completed their 
Table 1 Pilot school demographic summary

\begin{tabular}{|c|c|c|}
\hline & \multicolumn{2}{|c|}{ Proportion of pupils, \% } \\
\hline & Pilot school & National rate ${ }^{a}$ \\
\hline $\begin{array}{l}\text { Pupils with SEN statements or supported } \\
\text { on School Action Plus }\end{array}$ & 5.4 & 9.3 \\
\hline $\begin{array}{l}\text { Pupils at end of Key Stage } 4 \text { achieving } \\
\text { level } 2 \text { English and maths }\end{array}$ & 57 & 54 \\
\hline $\begin{array}{l}\text { Pupils achieving } 5 \text { or more } A^{*}-C \text { grade } \\
\text { GCSES including English and maths }\end{array}$ & 57 & 50 \\
\hline Pupils eligible for free school meals & 8.5 & 7.3 \\
\hline Overall pupil absence rate & 6.9 & 7.3 \\
\hline Persistent absence rate & 5.3 & 5.0 \\
\hline Ethnicity: BME & 9 & 18 \\
\hline
\end{tabular}

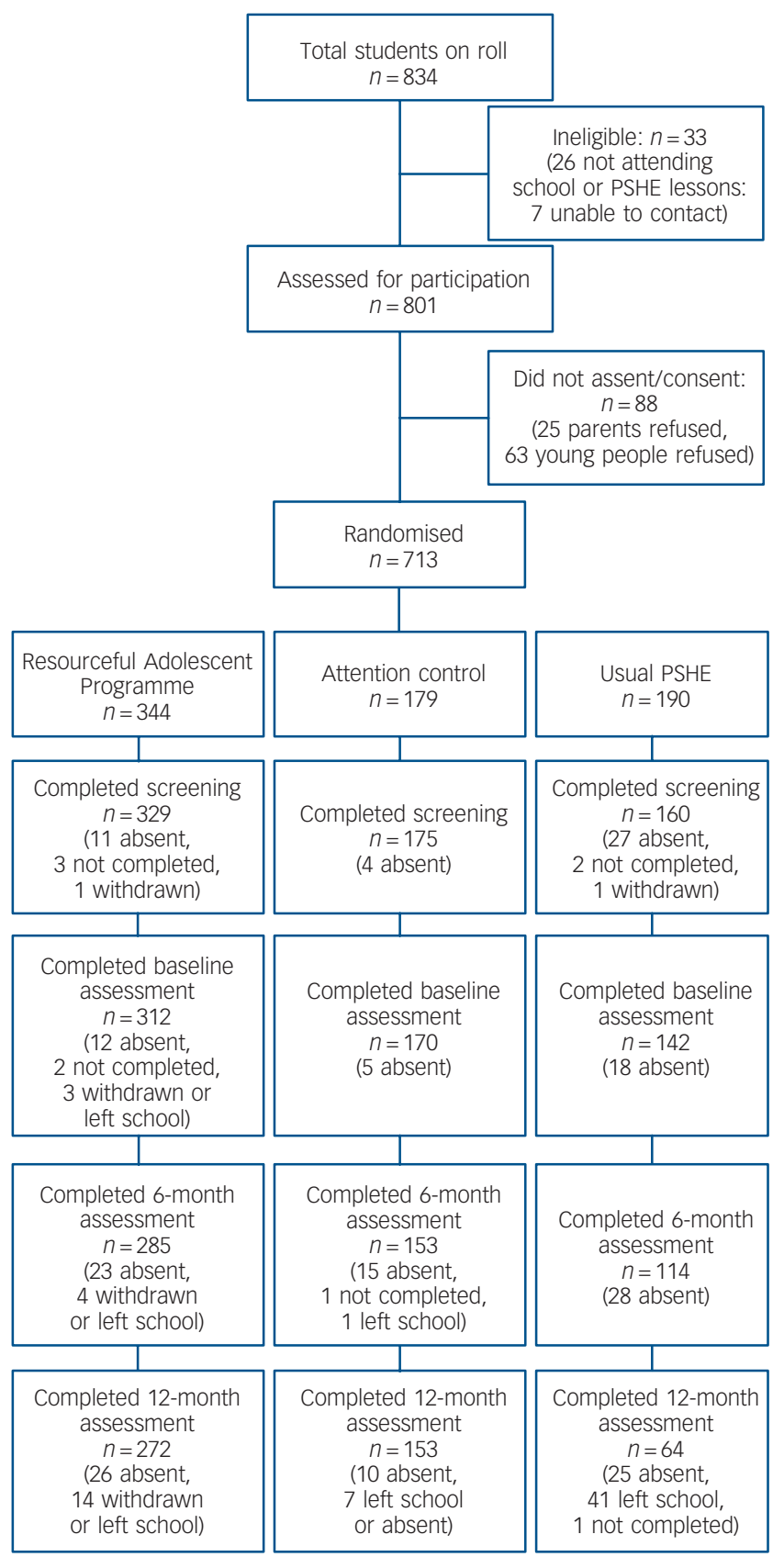

Fig. 1 Study profile. PSHE, personal, social and health education.
General Certificate of Secondary Education (GCSE) examinations and many had left school to transfer to other colleges or start work.

\section{Outcome measures}

Item completion on the SMFQ (the primary outcome measure) is summarised in Table 2 and highlights that completion was easy, with few missing data. Students were categorised as being at risk of developing a depressive disorder if they had scores of 5 or more on the SMFQ at both screening and baseline assessments (i.e. continuity of symptoms). A total of 191 (31\%) students who completed the SMFQ on both occasions were classified as being at high risk. Of these, $138(72 \%)$ were reassessed at 12 months.

\section{Symptom change}

The study was not powered to assess between-group differences on the primary outcome measure (SMFQ). Descriptive statistics are therefore presented in Table 3 for students at risk of depression in each trial arm at each assessment point. There was a decrease in SMFQ scores in all groups from screening and baseline assessment to 12 months.

\section{Intervention delivery}

The intervention was provided to students in years 8 and 10. All 9 RAP sessions were delivered to 15 classes, with the remaining class receiving 8 sessions. A total of 137 RAP sessions (95\%) were delivered as intended by two facilitators, with the other 7 sessions being led by one. Seven sessions were unexpectedly cancelled owing to adverse weather $(n=2)$, early school closure $(n=1)$, bank holidays $(n=1)$, examinations $(n=1)$, a school project day $(n=1)$ and PSHE being cancelled $(n=1)$.

\section{Session attendance}

Of the 409 eligible children in years 8 and 10, only 9 (2\%) failed to attend any RAP session. Of these children 5 were no longer at school, either having been expelled $(n=2)$ or moving school $(n=3)$ before the sessions started. Approximately half $(n=188)$ attended all nine sessions, with 357 (87\%) attending seven or more sessions.

\begin{tabular}{|c|c|c|c|}
\hline & $\begin{array}{c}\text { RAP } \\
(n=344)\end{array}$ & $\begin{array}{c}\text { Attention } \\
\text { control } \\
(n=179)\end{array}$ & $\begin{array}{l}\text { Usual PSHE } \\
\qquad(n=190)\end{array}$ \\
\hline \multicolumn{4}{|l|}{ Screening } \\
\hline All items complete & 326 & 171 & 15 \\
\hline One or more missing & 2 & 4 & 3 \\
\hline Students absent & 16 & 4 & 30 \\
\hline \multicolumn{4}{|l|}{ Baseline } \\
\hline All items complete & 311 & 172 & 169 \\
\hline One or more missing & 7 & 1 & 0 \\
\hline Students absent & 26 & 6 & 21 \\
\hline \multicolumn{4}{|l|}{6 months } \\
\hline All items complete & 301 & 158 & 141 \\
\hline One or more missing & 5 & 0 & 0 \\
\hline Students absent & 38 & 21 & 49 \\
\hline \multicolumn{4}{|l|}{12 months } \\
\hline All items complete & 291 & 157 & 75 \\
\hline One or more missing & 1 & 3 & 0 \\
\hline Students absent & 52 & 19 & 115 \\
\hline
\end{tabular}




\section{Overlap between RAP and usual PSHE}

Assessment of the contents of RAP and usual PSHE by lesson facilitators on a 5-point scale showed significant between-group differences on most variables (Table 4). The RAP facilitators rated the coverage of self-esteem, emotional awareness and positive thinking significantly higher compared with the PSHE facilitators, who gave highest ratings to the coverage of topics traditionally covered in this subject (bullying, smoking, drugs, alcohol, sex education, ethical issues, diversity, religion and citizenship). There was no significant difference between the groups in the specific focus on depression, although RAP facilitators rated the direct focus on mental health more highly.

\section{Acceptability of RAP}

\section{Student feedback}

Individual semi-structured interviews were undertaken with nine year 8 and ten year 10 students who took part in RAP. Overall feedback was supportive, with students liking the programme content, positive focus and the way in which the individual sessions built upon each other. A year 10 student commented:

'I'm sort of a negative person but it made me realise what maybe I need to improve things.'

Another reported:

I'm quite negative so it's made me think about maybe sort of changing how I think.' Similar comments were reported by year 8 students, for example: 'It made people think a bit more about how they could help themselves when they've been sad.'
The accompanying workbook was liked by most younger students. For example:

'The layout was good and the design fantastic.' (year 8 student)

Some older students thought that it was pitched at a younger level:

'I think it might have been a little childish because of some of the animations.' (year 10 student)

Some students expressed a preference for more activities, role plays and discussions:

'Like we did the role playing stuff to get everybody involved and contributing.' (year 8 student)

The video clips were seen as outdated and unclear:

'They were helpful but just a bit old.' (year 10 student)

The sessions that students found most helpful were those focusing on problem-solving, emotional recognition, the connection between thoughts and feelings, thought checking and relaxation. Those that focused on identifying and changing unhelpful thoughts were seen as repetitive and the support network session was considered by some to be too long:

'I thought it was a good message but they shouldn't have taken a whole lesson to do it.' (year 8 student)

\section{Teacher feedback}

A focus group was undertaken with the eight teachers whose classes received RAP. Initially teachers were concerned about addressing mental health in a group but by the end of the programme felt reassured:

Table 3 Scores on the Short Mood and Feelings Questionnaire (SMFQ) of students at risk of depression in each study group

\begin{tabular}{|lcccc|} 
& \multicolumn{4}{c}{ SMFQ score, mean (s.d.) } \\
\cline { 2 - 5 } & \multicolumn{1}{c}{ Screening } & Baseline & 6 months & 12 months \\
\hline RAP group & $11.89(5.31)(n=93)$ & $11.00(4.96)(n=93)$ & $9.86(6.46)(n=86)$ & $9.03(7.03)(n=78)$ \\
\hline Attention control group & $11.88(5.77)(n=48)$ & $12.22(6.26)(n=48)$ & $12.13(6.26)(n=39)$ & $10.32(6.39)(n=40)$ \\
\hline Usual PSHE group & $10.40(4.48)(n=50)$ & $10.66(4.89)(n=50)$ & $8.24(4.79)(n=34)$ & $9.05(6.03)(n=20)$ \\
PSHE, personal, social and health education; RAP, Resourceful Adolescent Programme. & & & \\
\hline
\end{tabular}

Table 4 Comparison between the Resourceful Adolescent Programme (RAP) and attention control content

\begin{tabular}{|c|c|c|c|c|c|}
\hline & \multicolumn{2}{|c|}{$\mathrm{RAP}^{\mathrm{a}}$} & \multicolumn{2}{|c|}{ Attention control ${ }^{a}$} & \multirow{2}{*}{$\begin{array}{l}\text { Difference in mean scores } \\
\qquad(95 \% \mathrm{Cl})\end{array}$} \\
\hline & $n$ & Mean (s.d.) & $n$ & Mean (s.d.) & \\
\hline How much were interpersonal relationships covered in this lesson? & 279 & $2.83(1.18)$ & 128 & $2.02(1.45)$ & 0.81 (0.54 to 1.07$)$ \\
\hline How much was bullying covered in this lesson? & 278 & $0.38(0.66)$ & 128 & $0.97(1.38)$ & $-0.59(-0.79$ to -0.39$)$ \\
\hline How much was self-esteem covered in this lesson? & 279 & $1.59(1.37)$ & 128 & $0.88(1.11)$ & $0.71(0.45$ to 0.99$)$ \\
\hline How much were feelings/emotions covered in this lesson? & 279 & $3.22(0.95)$ & 128 & $1.20(1.21)$ & 2.02 (1.80 to 2.24$)$ \\
\hline How much was smoking covered in this lesson? & 279 & $0.12(0.38)$ & 128 & $0.81(1.42)$ & $-0.69(-0.87$ to -0.51$)$ \\
\hline How much were drugs covered in this lesson? & 279 & $0.19(0.51)$ & 128 & $1.40(1.82)$ & $-1.21(-1.44$ to -0.97$)$ \\
\hline How much was alcohol covered in this lesson? & 279 & $0.25(0.52)$ & 128 & $0.91(1.40)$ & $-0.66(-0.85$ to -0.48$)$ \\
\hline How much were sex and/or contraception covered in this lesson? & 279 & $0.18(0.49)$ & 128 & $0.91(1.61)$ & $-0.73(-0.93$ to -0.52$)$ \\
\hline How much were ethical issues covered in this lesson? & 279 & $0.31(0.84)$ & 128 & $0.54(1.15)$ & $-0.23(-0.43$ to -0.28$)$ \\
\hline How much were green issues covered in this lesson? & 279 & $0.01(0.12)$ & 128 & $0.00(0.00)$ & $0.01(-0.01$ to 0.03$)$ \\
\hline How much were diversity and ethnicity covered in this lesson? & 278 & $0.18(0.54)$ & 128 & $0.88(1.58)$ & $-0.70(-0.90$ to -0.48$)$ \\
\hline How much was religion covered in this lesson? & 278 & $0.07(0.25)$ & 128 & $0.72(1.39)$ & $-0.65(-0.82$ to -0.48$)$ \\
\hline How much was problem-solving covered in this lesson? & 278 & $2.67(1.22)$ & 128 & $1.65(1.17)$ & $1.02(0.77$ to 1.28$)$ \\
\hline How much was thinking in positive ways covered in this lesson? & 278 & $2.92(1.07)$ & 172 & $0.98(0.96)$ & 1.94 (1.73 to 2.17$)$ \\
\hline How much was citizenship covered in this lesson? & 279 & $0.16(0.48)$ & 128 & $1.17(1.27)$ & $-1.01(-1.18$ to -0.84$)$ \\
\hline How much was depression covered in this lesson? & 279 & $0.83(0.98)$ & 128 & $0.72(1.08)$ & $0.11(-0.10$ to 0.33$)$ \\
\hline Overall, how engaged were students with this session? & 279 & $3.06(0.86)$ & 128 & $2.30(1.22)$ & $0.76(0.54$ to 0.97$)$ \\
\hline How much did this session directly focus upon mental health issues? & 279 & $2.27(0.99)$ & 128 & $0.69(0.89)$ & 1.58 (1.38 to 1.78$)$ \\
\hline
\end{tabular}


'I thought it was brilliant to be honest. I really enjoyed it. I mean I must admit I - we sort of had a bit of conversation a few months back. I had a few concerns really. Probably from the lack of my understanding perhaps more than anything.

The teachers were positive about the programme facilitators leading the sessions and the way in which assessment were conducted. They felt the concepts in the programme were memorable for themselves as well as for the students:

'I don't know about you but I find myself going home thinking this is self-talk, I'm falling into a negative thinking trap [laughter]. You do find yourself saying "I'm snowballing", but you know they really latched onto those key words.

'I thought my year eights weren't engaged at all - I've got some interesting characters - and then the last session that I had they did a recap of the whole thing and someone in that group could remember every single part [of the programme].'

It was felt that the benefits of the programme might not necessarily be obvious immediately, but that the skills students acquired could be useful as and when they encountered problems in their lives: 'I think a lot of what's in here actually the students wouldn't have been conscious of absorbing it until they need it.'

Teachers liked the content of the programme but at times felt it was pitched more towards the younger students (year 8) and may not have stretched the most able students:

'I think for some of our brighter students [the workbook] would almost be slightly patronising.'

Teachers also raised concerns about the ability of less able students to engage with RAP:

'Although they remembered some of the concepts, the lessons seemed very similar to them and actually they weren't able to separate [the concepts] in their mind because they weren't some of the more able students. They weren't able to separate, you know, the different kind of techniques they were being given.'

Disruptive student behaviour was also a major issue, particularly if students became disengaged (e.g. with some of the older video clips) and where there was a large amount of group discussion involved for students who were not used to learning in this way. In classes where disruptive behaviour was a problem, moving between small-group and whole-class activities was difficult to manage. The ability of facilitators to manage student behaviour came to light as a salient issue during this feasibility study. The additional support from external staff was viewed as essential, particularly with regard to working with large classes and being able to manage the small group activities:

'If I'm being honest about whether this would work as it stands as a programme, without the support that we've had it wouldn't. I don't think it would be possible in a class of twenty-five plus to run the kind of discussions that we've needed to run the programme.

In terms of delivery the teachers felt that the sessions were sometimes repetitive, and they had many ideas about how sessions could be more interactive and engaging, such as making the graphics in the workbooks more age-appropriate, updating some of the materials (particularly the video clips), and using more practical tasks in addition to the discussions.

\section{Discussion}

Schools offer a convenient location for the widespread dissemination of mental health prevention programmes for children and adolescents. However, although schools provide a natural focus for prevention, little attention has been paid to the feasibility of delivering such interventions within educational settings and whether methodologically robust evaluations are possible within this context. This feasibility study has demonstrated that the delivery and evaluation of a school-based depression prevention programme is practical within the UK educational context. In the school studied, $96 \%$ of students on roll were actually attending school and able to access and potentially benefit from the interventions. The complete nine-session Resourceful Adolescent Programme was delivered to all but one class with $95 \%$ of sessions being delivered as intended by two trained facilitators. Of the students who received RAP, almost $90 \%$ attended seven or more of the nine sessions. However, in this pilot study RAP was delivered to only two of the school year groups and it is unclear whether delivery and attendance rates would be similar for the other year groups. Indeed, delivering to year 11 students might be particularly problematic as the main focus for these students is on preparing for their GCSEs. Nonetheless, these results are encouraging and suggest that the majority of students in secondary school would be able to access and receive sufficient dosage from mental health prevention programmes.

\section{Comparison groups}

Providing appropriate comparison groups against which active interventions can be assessed in schools is challenging. Schools need to ensure that they deliver the national curriculum and inevitably there will be some overlap in content with more focused mental health programmes. Facilitator ratings completed at the end of each session revealed no difference between the RAP and enhanced groups in the specific focus on depression, although there were significant between-group differences in other aspects of content. The RAP is based on CBT, with facilitators rating the emphasis on emotional awareness and positive thinking significantly more highly than those facilitating the usual PSHE group. This suggests that the content of RAP and PSHE are sufficiently different and that PSHE as provided by the school is an acceptable comparator against which focused mental health prevention programmes can be compared.

\section{Methodology}

In terms of research methodology the consent process was both practical and acceptable, with consent to complete study assessments approaching 90\%. Retention rates declined over time, although $78 \%$ were retained at the 12 -month follow-up. Retention rates of year 11 students were the lowest $(45 \%)$ as many had left school. Alternative ways of contacting older students, such as mobile telephones, email and putting the assessments online, will be considered to maximise retention in the main trial. In relation to assessment measures, there were few missing data on the primary outcome measure, suggesting that it is acceptable to students. The criteria for classifying students as 'at risk' in terms of severity and persistence of symptoms resulted in approximately $30 \%$ of students being identified. This is higher than predicted (20\%) but nonetheless appears an acceptable alternative to undertaking diagnostic assessments to identify students with elevated and persistent symptoms of low mood.

\section{Future research}

The session contents and exercises will be modified in the light of the qualitative feedback to ensure that the materials are engaging, appealing and relevant to all age groups. Greater emphasis also needs to be placed on working in a school environment with whole classes and on working alongside teachers during training and supervision of facilitators.

To conclude, these results support the premise that universal depression prevention programmes delivered in schools have the potential to reach the majority of students. Delivery by external health personnel is feasible and the intervention was viewed as acceptable by students and teaching staff. There were some concerns about the developmental pitch of the materials and a particular problem in retaining year 11 students. This study has achieved good recruitment, reasonable retention and usual PSHE appear sufficiently different to RAP provide an appropriate comparator. 
Further research is now required to determine the effectiveness of depression prevention programmes delivered in schools.

Paul Stallard, PhD, Rhiannon Buck, PhD, Department for Health, University of Bath, UK

Correspondence: Professor P. Stallard, Child and Adolescent Mental Health Research Group, 22-23 Eastwood, Department for Health, University of Bath, Bath BA2 7AY, UK. Email: p.stallard@bath.ac.uk

\section{Funding}

This study was funded by the National Institute of Health Research Health Technology Assessment (06/37/04). The views and opinions expressed therein are those of the authors and do not necessarily reflect those of the HTA programme, NIHR, NHS or the Department and do not
of Health.

\section{References}

1 Costello EJ, Erkanil A, Angold A. Is there an epidemic of child or adolescent depression? J Child Psychol Psychiatry 2006; 47: 1263-71.

2 Birmaher B, Ryan ND, Williamson DE, Brent DA, Kaufman J, Dahl RE, et al. Childhood and adolescent depression: a review of the past 10 years. Part 1. J Am Acad Child Adolesc Psychiatry 1996; 35: 1427-39.

3 Lewinsohn PM, Rhode P, Seeley JR. Major depressive disorder in older adolescents: prevalence, risk factors and clinical implications. Clin Psychol Rev 1998; 18: 765-94.

4 Gould MS, Greenberg T, Velting DM, Shaffer D. Youth suicide risk and preventative interventions: a review of the past 10 years. J Am Acad Child Adolesc Psychiatry 2003; 42: 386-405.

5 Kim-Cohen J, Caspi A, Moffitt TE, Harrington H, Milne BJ, Poulton R. Prior juvenile diagnoses in adults with mental disorder developmental follow-back of a prospective-longitudinal cohort. Arch Gen Psychiatry 2003; 60: 709-17.

6 Kovacs M. Presentation and course of major depressive disorder during childhood and later years of the life span. J Am Acad Child Adolesc Psychiatry 1996; 35: 705-15.

7 Lewinsohn PM, Rhode P, Seeley JR, Klein DN, Gotlib IH. Natural course of adolescent major depressive disorder in a community sample: predictors of recurrence in young adults. Am J Psychiatry 2000; 157: 1584-91.

8 Goodyer I, Dubicka B, Wilkinson P, Kelvin R, Roberts C, Byford S, et al. Selective serotonin reuptake inhibitors (SSRIS) and routine specialist care with and without cognitive behaviour therapy in adolescents with major depression: randomised controlled trial. BMJ 2007; 335: 142.

9 March J, Silva S, Curry J, Wells K, Fairbank J, Burns B, et al. The Treatment for Adolescents with Depression Study (TADS): outcomes over 1 year of naturalistic follow-up. Am J Psychiatry 2009; 166: 1141-9.

10 Brent D, Emslie G, Clarke G, Wagner KD, Asarnow JR, Keller M, et al. Switching to another SSRI or to venlafaxine with or without cognitive behaviour therapy for adolescents with SSRI-resistant depression. The TORDIA randomised controlled trial. JAMA 2008; 299: 901-13.

11 Coyle JT, Pine DS, Charney DS, Lewis L, Nemeroff CB, Carlson GA, et al. Bottom of Form Depression and Bipolar Support Alliance consensus statement on the unmet needs in diagnosis and treatment of mood disorders in children and adolescents. J Am Acad Child Adolesc Psychiatry 2003; 42: 1494-503.

12 Ford $\mathrm{T}$, Hamilton $\mathrm{H}$, Meltzer $\mathrm{H}$, Goodman R. Predictors of service use for mental health problems amongst British school children. Child Adolesc Ment Health 2008; 13: 32-40.

13 Giesen F, Searle A, Sawyer M. Identifying and implementing prevention programmes for childhood mental health problems. J Paediatr Child Health 2007; 43: 785-9.

14 Department for Children, Schools and Families. Targeted Mental Health in Schools Project: Using the Evidence to Inform Your Approach: A Practical Guide for Head Teachers and Commissioners. DCSF, 2008.

15 Department for Education and Skills. Primary National Strategy. Excellence and Enjoyment: Social and Emotional Aspects of Learning. DfES, 2005.

16 Humphrey N, Lendrum A, Wigelsworth M. Social and Emotional Aspects of Learning (SEAL) Programme in Secondary Schools: National Evaluation. DFE-RR049. Department for Education, 2010.

17 Sawyer MG, Pfeiffer S, Spence SH, Bond L, Graetz B, Kay D, et al. School-based prevention of depression: a randomised controlled study of the beyondblue schools research initiative. J Child Psychol Psychiatry 2010; 51: 199-209.

18 Challen A, Noden P, West A, Machin S. UK Resilience Programme Evaluation: Interim Report. RR094. Department for Children, Schools and Families, 2009.

19 Horowitz JL. Garber J. The prevention of depressive symptoms in children and adolescents: a meta-analytic review. J Consult Clin Psychol 2006; 74: 401-15.

20 Calear AL, Christensen H. Systematic review of school-based prevention and early intervention programs for depression. J Adolesc 2010; 33: 429-38.

21 Challen A, Noden P, West A, Machin S. UK Resilience Programme Evaluation. Final Report. Department for Education, 2011.

22 Spence SH, Shortt AL. Research review: can we justify the widespread dissemination of universal, school based interventions for the prevention of depression among children and adolescents? J Child Psychol Psychiatry 2007; 48: 526-42.

23 Stallard P, Montgomery AA, Araya R, Anderson R, Lewis G, Sayal K, et al. Protocol for a randomised controlled trial of a school based cognitive behaviour therapy (CBT) intervention to prevent depression in high risk adolescents (PROMISE). Trials 2010; 11: 114.

24 Angold A, Costello E, Messer S, Pickles A, Winder F, Silver D. Development of a short questionnaire for use in epidemiological studies of depression in children and adolescents. Int J Methods Psychiatr Res 1995; 5: 237-49.

25 Shochet IM, Dadds MR, Holland D, Whitefield K, Harnett PH, Osgarby SM. The efficacy of a universal school-based program to prevent adolescent depression. J Clin Child Psychol 2001; 30: 303-15.

26 Shochet I, Ham D. Universal school-based approaches to preventing adolescent depression: past findings and future directions of the Resourceful Adolescent Program. Int J Ment Health Promotion 2004; 6: 17-25.

27 Merry S, McDowell H, Wild CJ, Bir J, Cunliffe R. A randomized placebocontrolled trial of a school-based depression prevention program. J Am Acad Child Adolesc Psychiatry 2004; 43: 538-47.

28 Rivet-Duval E, Heriot S, Hunt C. Preventing adolescent depression in Mauritius: a universal school-based program. Child Adolesc Ment Health 2011; 16: 86-91. 